\title{
Accessibility and Utilization of Health Information by Rural Women in Vihiga County, Kenya
}

\author{
Serah Odini
}

\begin{abstract}
Findings showed that there was a strong need for health information of all types. Most of the information needed related to day - to-day health problems and that woman have health information needs which are not adequately satisfied by the existing information systems and services due to poverty, lack of awareness toadequate health information resources, illiteracy, and poor information communication channels, among others. Information was accessed mainly through face - to - face communication, cell phone, radio, and television. Choice of information sources was influenced by the respondent's level of education, income, age, occupation and distance to and location of information sources. The paper concludes by recommending appropriate strategies necessary for improving information accessibility in rural areas of Vihiga County in Kenya at large. In view of the above, there is need to improve the existing health information infrastructure in the county by introducing the use of suitable ICTs such as radio, TV, among others. Information providers should regularly identify the health information needs of the women since these will keep changing from time to time and base health information services on identified needs. Health information should be repackaged and disseminated to the women in appropriate forms suitable for them, in line with their levels of education for easy access and use. Thereis needalso to enhance the skills of rural women through equitable training and education.This will enable them to access and use timely and adequate health information, and consequently improve their health.
\end{abstract}

Keywords: Women, Health, Women in Kenya, Rural areas, health information, Information, Health SDGs.

\section{Introduction}

According to the United Nations Commission on the Status of Women (2003), rural women experience poorer health outcomes and have less access to health care than urban women. Many rural areas have limited numbers of health care providers, especially women's health providers. Women are not only the most infected within the societies especially with HIV/AIDS related illnesses; they are also caregivers ofHIV orphans and also care for the sick and older people. With all these before them, they usually have no time to seek relevant health information even when they know they need it. Making decisions using wrong or inaccurate information however mean wrong decisions which may lead to death especially information concerning delicate health issues.

In Kenya health information is provided through the Ministry of Health and the Ministry of Public Health and Sanitation. In line with the Government policy to decentralize service delivery to the counties, the Ministry of health has decentralized a significant portion of the health system under the local government. Women have responsibilities for the public health of their populations and for the day to day operation of the health services in their communities. Specific campaigns to send information to rural women include the prevention of mother to child transmission, immunization, nutrition, and water hygiene education programme, among others (Bii and Otike, 2003).However, a lot more is needed at the rural areas to place women at the centreof the ICTs development discourse, and to see a great deal more improvement of the quality of life of women.

Access to health services and the quality of care administered at all levels of health care have been considered as the central determinants of health outcomes. Efforts to eliminate inequalities in the access of basic health care services have been emphasized for the overall improvement of health in developing countries through the Ministries of health and globally the World Health Organization. In 2013 the Government of Kenya enforced a policy for free maternal health services across all government healthcare institutions in its quest to reduce maternal morbidity and mortality rates and to improve the survival rates of their children in a run up to the attainment of MDG 4 and 5 respectively by September 2015, and Vision 2030

The study was carried out in Vihiga County in Western Province of Kenya. This study area was chosen because it is very far away from Nairobi city which is where better health services are concentrated. The researcher therefore considered it crucial to establish how women in this rural area access, and use health information. The study focused on rural women between the ages of 15- 70 years because they confront illiteracy, poverty, poor sanitation, and medical facilities that are inadequate, physically, and economically inadequate. These rural women are usually housewives, single parents, shopkeepers, farmers, and are also involved in different activities in the communality, such as membership of different associations, projects, and programs, for example, burial societies, crime prevention traditional groups, women's groups, among others. The county also has poor information infrastructure and women's potential is grossly underutilized. (Odini, 2009)

\section{Statement of the Problem}

Availability and accessibility to adequate, current, and effective information systems are key factors to better healthcare. Unfortunately, information services in the county are limited and where they exist, they are generally ineffective in meeting the health information needs of women. Mostly, these women live in very remote localities which are inaccessible due to poor road infrastructure, electricity, among others. These situations hinder the accessibility of information by women and consequently the 


\section{International Journal of Science and Research (IJSR) \\ ISSN (Online): 2319-7064 \\ Index Copernicus Value (2013): 6.14 | Impact Factor (2015): 6.391}

utilization of the information they require to improve their health. Even if there were health information services in the county, women would not make full use of the services, as majority of them are illiterate, ignorant, and poor to use appropriate and timely health information on various health issues such as family planning and reproductive services (Odini, 2009). This situation is aggravated by poor packaging and exchange of existing health information due to poor communication channels in the county.

The absence of skilled personnel, language barrier, has also added to the problems of inaccessibility and poor use of health information by the women in the county. In addition, few studies have been conducted to establish the effectiveness and efficiency of the medium used to disseminate health information to women in their efforts to reduce health problems such as maternal mortality, family planning, among others.

\section{Aim of the Study}

The study investigated accessibility and utilization of health information by rural women in Vihiga County in Western Kenya, with a view of making suggestions for improvement.

The specific objectives of the study were to:

- Establish the health problems and common diseases experienced by rural women in Vihiga County.

- Determine the health information required and the sources consulted by the women to satisfy their information needs

- Establish the government strategies put in place to ensure the accessibility and utilization of health information among women

- Identify what hinders accessibility and utilization of health information by rural women

- Make suggestions on how health information can be accessed and utilized to improve women's health in the County.

\section{Literature Review}

The WHO (1995) report notes that if the goal of health - for - all is to be attained, more attention must be given to women's health and their roles in health and development. The report came up with strategies based on the recognition that women's health and roles depend on broad considerations such as employment, education and social status, equitable access to economic resources, and political power. The WHO (2009) further states that primary healthcare is about promotion of health and prevention of illnesses. This can also be achieved through provision of information meant to inform and educate communities on their health. The WHO/ UNICEF Conference in 1978 identified shortages of adequate health information, personnel as contributing factors to the collapse of some of the health care systems.

Lwoga et al. (1996) notes that information needs of rural people are varied due to demographic, social, cultural an economic factors, among others. Odini (2009) adds that information needs of rural women in Kenya relates mainly to their level of poverty. She asserts that limited information accessibility is caused by various reasons including poor infrastructure, among others. She identifies lack of skills, cost of information andgeographical isolation, and so on, as the main challenges to effective use of information among rural women in Kenya.

Kaane(1997) notes that the achievement of primary health care calls for the involvement of individuals in their own healthcare and improvements in health for all. This can come about only through information and education to the public to enable them to make healthy choices. According to her, the concept of primary healthcare has been in cooperated in many national programmes. She asserts that many such programmes in developing countries have lost their focus and are curative. Momudu (2002) notes that rural women in Africa experience all kinds of problems which include poverty, discrimination, cultural and political, illiteracy, amongothers. According to Mooko (2002), rural people need various health information on common diseases, specific causes, symptoms, transmission, and where to get the best treatment. Bii (1998) adds that oral and audio sources are the most commonly used media rural people obtain health information.

According to the report by WHO (2009), the Government of Kenya performs various activities such as, a variety of policies, programmes and activities that are aimed at or contribute to enhancing women's access to health services and improving their health status. These include Maternal and Child Health, and family planning programmes; Safe motherhood initiative, which operates in each clinic in the Country.Odini (2009) notes that access and use of adequate and quality information such as family planning can empower rural women to alleviate poverty and that good health is one of the critical components influencing the potential of rural women to move out of poverty.The African Economic Research Consortium (2009) argues that although there is broad consensus among health care workers and policy makers about the importance service quality healthcare demand, improvements in service quality have either not been undertaken orhave been implemented without the necessary information about their impact on the demand for healthcare.

\section{Methodology}

The study was carried out in Western Kenya using a case study of Vihiga County. The population of the study comprised 150 women residents of Vihiga County aged $15-$ 70 who were involved in various activities, which helped them to improve theirhealth status. The study used both qualitative and quantitative approaches. The qualitative approach aimedat collecting participant's perspectives about real phenomena under study. The Vihiga County Development Plan (2002 - 2008) gave the population size of Vihiga County as 150, 98 women aged between 15 and 70 . The statistics lists constituted the sampling frame. It is from this population $(150,198)$ that the sample for this study was drawn. Different sampling techniques were used which included: stratified, systematic random sampling, snowball sampling, and purposive sampling methods. As a result of some constrains such as finance, it was decided at random that one tenth of one percent of the entire population (that is 


\section{International Journal of Science and Research (IJSR) \\ ISSN (Online): 2319-7064}

Index Copernicus Value (2013): 6.14 | Impact Factor (2015): 6.391

$1 / 10 /$ of $1 / 100 \times p$, where $p$ is the county population size of $150,198)$ be used, which resulted to 150 women.Consequently this number of women was selected at random from each of the sub - county using snowball sampling method. In addition, five informants who in one way or the other were involved in the provision of healthinformation to rural women were consulted.Data was collected through a variety of methods such as semi structured interviewing, self-instructed questionnaire, and documentation review. Qualitative data was analysed thematically based on the objectives of the study, while quantitative data was analysed using descriptive statistics and presented using frequency distribution tables.

\section{Findings Demographic and social - economic characteristics of the Respondents}

Out of a total of 150 respondents interviewed, $82(68 \%)$ were aged between $51-60$ years, a total of $110(92 \%)$ of respondents were married. With regard to level of education, results showed that most respondents a total of $98(82 \%)$ women who participated in the study had no access to formal education. Of those interviewed, $96(80 \%)$ were unemployed housewives and practiced small scale farming. The respondents had large numbers of dependents. These included children, parents, sisters, cousins, and brothers. When asked to state the number of children each respondent had, most respondents $85(71 \%)$ had between $6-10$ children. The respondents were asked to indicate their main source of income and $92(77 \%)$ respondents met their household income from their husbands, 109 (91\%) from the sale of farm produce.

\section{Common diseases suffered by rural women and source of treatment}

The study attempted to establish the common diseases suffered by women in VihigaCounty. The findings are presented in Table 1 below:

Table 2: Common Diseases reported by women $n=150$

\begin{tabular}{|c|c|c|}
\hline Common Diseases & Respondents & Percentage \\
\hline Malaria & 148 & 99 \\
\hline High blood pressure & 142 & 92 \\
\hline Flu and cough & 119 & 79 \\
\hline Body pain and backache & 100 & 67 \\
\hline Headache & 97 & 65 \\
\hline Pneumonia & 96 & 64 \\
\hline Eye/ear/ throat & 94 & 63 \\
\hline Typhoid & 88 & 59 \\
\hline Respiratory infection & 88 & 59 \\
\hline Diarrhoea & 72 & 48 \\
\hline Asthma & 65 & 43 \\
\hline Dental problems & 63 & 42 \\
\hline Pregnancy and Pre natal care & 62 & 41 \\
\hline Stress/Mental cases & 60 & 40 \\
\hline Tuberculosis & 45 & 30 \\
\hline heart/ Stroke & 43 & 29 \\
\hline Intestinal Worms & 43 & 29 \\
\hline Bleeding/ Anaemia & 42 & 28 \\
\hline Ulcers & 42 & 28 \\
\hline STDs/ HIV/AIDS & 38 & 25 \\
\hline Skin problems & 24 & 16 \\
\hline Diabetes & 20 & 13 \\
\hline Jiggers & 17 & 11 \\
\hline Wounds & 17 & 11 \\
\hline
\end{tabular}

\section{- Multiple Responses}

Majority 148 (99\%), women cited malaria as the most common disease suffered by women in the study area while blood pressure was $142(92 \%)$, followed by flu, cold 119 (79\%), body pain $100(67 \%)$, and headache 97 (65\%). Pneumonia with 96 (64\%)was also indicated as a significant health problem faced by the women. Interestingly, HIV/AIDs was not featured amongst the top health problems faced bythe women as only $38(25 \%)$ of the women indicated it to be a problem. This could be that HIV/AIDs infection is not common among elderly women in rural areas.

The study revealed that majority of the respondents had visited government health centres to search for information on treatment of various health problems. This was followed by traditional healers, government hospitals, Mission hospitals, Private Clinics, Self- Medication, and pharmacy, among others. This shows that women in the county prefer government health centres to seek for help with the hope of getting free healthcare services. This was because rural women could not afford the cost of treatment in private hospitals, among many other reasons. These results confirmed the constant lack of drugs in the government facilities. Even after the introduction of free maternity services in the government facilities, drugs are consistently inadequate and patients are therefore forced to purchase most of the prescribed drugs from private clinics and pharmacies. This means women lack access to health quality information, and thereforego where they can get cheaper even nearer place to get drugs from the government facilities.

\section{The Kindof healthinformation required by women}

Results on the kind of health information women needed and the analysis of the responses is presented in table 2 below:

Table 3: The health information required byrural women $n$ $=150$

\begin{tabular}{|c|c|c|}
\hline Health information required & Respondents & Percentage \\
\hline Treatment of various diseases & 148 & 99 \\
\hline Availability of drugs & 142 & 95 \\
\hline Immunization & 124 & 83 \\
\hline Nutrition & 122 & 81 \\
\hline Child care & 120 & 80 \\
\hline Maternal health and Family Planning & 119 & 79 \\
\hline HIV/AIDS and STDs treatment & 100 & 67 \\
\hline Personal hygiene & 84 & 56 \\
\hline Environmental hygiene & 50 & 33 \\
\hline Water and sanitation & 38 & 39 \\
\hline Social support measures & 35 & 25 \\
\hline Legislation and policy imperatives & 24 & 16 \\
\hline Malnutrition & 20 & 13 \\
\hline Women's organizations & 18 & 12 \\
\hline
\end{tabular}

\section{- Multiple responses}

Respondents were asked to indicate the kind of health information they needed to address their health problems. Majority respondents needed information on treatment of various diseases 148 (99\%), availability of drugs 142 (95\%), immunization $124(83 \%)$, nutrition 122 (81\%), child care $120(80 \%)$, maternal health and family planning 119 (79), among others as indicated in Table 2 above. Furthermore, results showed that only $20(13 \%)$ needed information on 


\section{International Journal of Science and Research (IJSR) \\ ISSN (Online): 2319-7064 \\ Index Copernicus Value (2013): 6.14 | Impact Factor (2015): 6.391}

malnutrition. These results indicatethat manywomen need adequate information totreat their identified healthproblems compared to the need for good nutrition. This could be rural women are not aware of their state of malnutrition.

\section{Information sources and services consulted for required information}

Majority women 136 (91\%) used relatives as their main source of information, while134 (89\%) of women used friends, government health centres were 132 (88\%), and so on. See table 4 below:

Table 4: The sources consulted for required health information $\mathrm{n}=150$

\begin{tabular}{|c|c|c|}
\hline Health information Sources consulted & Respondents & Percentage \\
\hline Relatives & 136 & 91 \\
\hline Friends & 134 & 89 \\
\hline Government health Centres & 132 & 88 \\
\hline Government Hospitals & 130 & 87 \\
\hline Mobile phone & 128 & 85 \\
\hline Health talks at clinics & 124 & 83 \\
\hline Posters / leaflets & 123 & 82 \\
\hline Traditional healers & 120 & 80 \\
\hline Radio & 89 & 59 \\
\hline Television & 64 & 43 \\
\hline Mission Hospitals & 60 & 40 \\
\hline Quacks & 52 & 35 \\
\hline Herbalists & 45 & 30 \\
\hline Posters/charts & 38 & 25 \\
\hline Magazines & 30 & 20 \\
\hline Pamphlets, brochures & 26 & 17 \\
\hline Pharmacy & 20 & 13 \\
\hline Private clinic & 18 & 12 \\
\hline Newspapers & 15 & 10 \\
\hline Internet & 13 & 9 \\
\hline Books & 12 & 8 \\
\hline Church & 10 & 7 \\
\hline County "barazas" & 8 & 6 \\
\hline Women Group leaders & 7 & 5 \\
\hline Library & 6 & 4 \\
\hline Research organization & 5 & 3 \\
\hline Extension workers & 3 & 2 \\
\hline
\end{tabular}

\section{- Multiple responses}

The majority of women used relatives such as parents as their first source of health information. This was followed by government health centres, and government hospitals. This was because these were the nearest sources of information known to them and also not costly. This implies that knowledge of these information sources influenced information seeking behaviour and improved access and use of health information among the women. Mobile phone as a source of information accounted for about. (See Table 4).

\section{Strategies put in place to ensure access and use of health informationby rural women \\ Findings revealed that HV/Testing was known by 88 (58\%), Free maternity services, $85(56 \% \%)$ women knew Community health care workers $82(54 \%)$; home based care services 80 (53\%), while Beyond Zero(maternal health) 75 (50\%); community mobilization was known by $68(45 \%)$ women, among others. Very few women 5 (3), were aware of the Convention on the Rights of Women (See table 5 below. This was a very small number and indicates that women are not aware of their rights to access and use}

information neither are they aware of the strategies put in place to provide them with the necessary health information. This means even if the information is available they may not know that it is their right to access and use information.

Table 5: Health information programmes and strategies put in place to regulate access to health information.

\begin{tabular}{|c|c|c|}
\hline Strategies put in place & Respondents & Percentage \\
\hline HIV/ AIDS Testing & 88 & 58 \\
\hline Free maternal services & 85 & 56 \\
\hline Community health care workers & 82 & 54 \\
\hline Home Based Care & 80 & 53 \\
\hline Beyond Zero ( maternal health) & 75 & 50 \\
\hline Community mobilization & 68 & 45 \\
\hline $\begin{array}{c}\text { Research on concerning women issue } \\
\text { on topical issues }\end{array}$ & 67 & 44 \\
\hline International Development Partners & 60 & 40 \\
\hline Home visits & 52 & 35 \\
\hline Information policies & 50 & 33 \\
\hline $\begin{array}{c}\text { Non - Governmental and Community } \\
\text { based organizations }\end{array}$ & 45 & 30 \\
\hline National Aids Control Council & 39 & 26 \\
\hline Maternal and Child Health & 38 & 25 \\
\hline $\begin{array}{c}\text { National Reproductive Health services } \\
\text { Delivery }\end{array}$ & 36 & 24 \\
\hline Safe motherhood & 35 & 23 \\
\hline Constituency HIV/AIDS Committees & 30 & 20 \\
\hline The National Malaria strategy & 20 & 13 \\
\hline Women and Aids projects, & 20 & 13 \\
\hline Nutrition for mothers & 18 & 12 \\
\hline $\begin{array}{c}\text { Prevention of Mother to Child } \\
\text { Transmission (PMTCT) }\end{array}$ & 15 & 10 \\
\hline Community Mobilization & 11 & 7 \\
\hline Convention on the Rights of Women \\
\hline $\begin{array}{c}\text { Integrated Management of Childhood } \\
\text { Illnesses strategy }\end{array}$ & 10 & 6 \\
\hline International organizations & 2 & 3 \\
\hline
\end{tabular}

\section{- Multiple responses}

As indicated in Table 5 above, only 75 (50\%) respondents knew about the maternal health programme which could provide them with health information. The Beyond Zero promotion programme spearheaded by the First Lady Mrs Margret Kenyatta which has been given a lot of publication is yet to pick up. From table 5 above, results suggest that the free maternal services are not contributing to the intended objective of improving health service delivery as evidenced by the continued death of rural women from maternal related health problems, poverty, and lack of timely information on the available maternal services and transport services.

\section{Challenges experienced in accessing and using health information by rural women}

The study was interested in identifying the challenges faced by women in accessing and using information. Some respondents 148 (99\%) cited poverty and lack of productive resources, inadequate infrastructure was a problem to 145 $(96 \%)$, and inadequate maternal education 140 ( ).Others $138(92 \%)$ mentioned challenges such as ignorance and lack of awareness of various issues about their health, followed by low literacy levels $135(90 \%)$. The issue of lack of time to access health information was cited by 132 ( $88 \%)$, while distance to health information centres was reported as a challenge to $130(87 \%)$ as indicated in Table 6 below. 


\section{International Journal of Science and Research (IJSR) ISSN (Online): 2319-7064 \\ Index Copernicus Value (2013): 6.14 | Impact Factor (2015): 6.391}

Table 6: Challenges experienced in accessing andusing health information by rural women $n=150$

\begin{tabular}{|c|c|c|}
\hline $\begin{array}{c}\text { Challenges experienced in accessing } \\
\text { and using health information }\end{array}$ & Respondents & Percentage \\
\hline $\begin{array}{c}\text { Poverty and lack of information } \\
\text { resources }\end{array}$ & 148 & 99 \\
\hline $\begin{array}{c}\text { Poor infrastructure, electricity } \\
\text { Inadequate maternal education }\end{array}$ & 145 & 96 \\
\hline $\begin{array}{c}\text { Ignorance and lack of awareness on } \\
\text { various diseases }\end{array}$ & 138 & 93 \\
\hline Low literacy levels & 135 & 90 \\
\hline Time to seek health information & 132 & 88 \\
\hline Distance to health centres & 130 & 87 \\
\hline $\begin{array}{c}\text { High cost of accessing health } \\
\text { information }\end{array}$ & 130 & 87 \\
\hline Roads and transportation & 128 & 85 \\
\hline No proper guidance and counselling & 120 & 80 \\
\hline Poor health information service & 86 & 57 \\
\hline Inadequate policies and strategies & 82 & 55 \\
\hline Cultural barriers - Beliefs and customs & 74 & 49 \\
\hline Negligence - health professionals not \\
present & 56 & 37 \\
\hline Weather changes & 45 & 30 \\
\hline Inadequate skilled manpower & 32 & 21 \\
\hline Lack of health promotion activities & 30 & 20 \\
\hline Religious beliefs & 20 & 19 \\
\hline Unfriendly staff at the health centres & 18 & 12 \\
\hline
\end{tabular}

\section{- Multiple responses}

Table 6 above shows that access and use of health information was hampered by various reasons. An in - depth knowledge of how these factors influence information service accessibility is necessary for accessing and using effective health services by rural women. For effective information usage among rural women, it is important to investigate in detail how specific groups of rural women access and use information for meeting their healthdailyinformation needs. Key respondents also suggested that rural women should be empowered to access and use information to enable them improve their health

\section{Discussion of Findings}

The study findings showed that women in Vihiga County were faced with various problems such as poverty and lack of resources, lack of education and technology, poor infrastructure, high rate employment, and lack of information, among many others. Due to the problems above women in the study lack access to good health. This is in agreement with WHO (1995) that rural women are faced with various problems which include lack of employment, education, and health. If the health - for - all is to be attained, more attention must be given to solving women's problems in health and development

The common diseases suffered by the women included: malaria, headache, flu, cough, body pain, high blood pressure, among others. A study by Odwee(2006) identified similar common diseases suffered by women in Uganda. From his study findings it was revealed that rural women experienced varied specific health information needs such as: treatment of their various problems, causes, treatment, prevention, health centres, availability of drugs, immunization, nutrition, and so on. These results agree with the findings of Mooko (2002) that rural women have various health information needs in rural areas of Botwana.

All respondents needed a variety of health information related to their health problems.Majority needed information on treatment of various diseases 148 (97\%).Bii (2003) contents that rural people including women need various health information which included STDs diseases, nutrition, child care and personal hygiene, among others. The findings are also in consistent with a study by Odini(2009) on information needs of rural women which establishedthat women's occupation, age and level of education influenced the need for some type of healthinformation. The findings indicate and conclude that there is need for rural women to find out about various diseases, their causes, and treatment and that health professionals should provide rural women with relevant information linked to their health information needs and problems.

Virtually all the respondents relied on oral channels of information such as relatives and friends because these channels were available and easily accessible. Similar findings were also identified by Mooko (2006) that friends and relatives are the main sources of health information among rural areas. The finding also confirm that choice of information source was influenced by individual traits such as type of disease, age, level of education and income .Several studies including Rosenberg (1993) notes that African information is more interactive which do not see people in libraries or information centres. That such interpersonal providers of information are easily found, not controlled by time, and allow for flexibility in communication procedures.

Radioand television programmes were stated as sources of health information for 89 (59\% women within the villages. However, the findings contract those of Odini (2009) that rural women have busy schedules, limited access to information sources like radio, television, and newspapers due to their environment which, included, poverty, transportation, poor infrastructure, language barrier, illiteracy, and geographical isolation. The results of this study concurs with an earlier study conducted by Mooko ( 2006) which revealed that a very small number got health information though brochures, pamphlets given to women at the health centre, yet due to high rate of illiteracy, women missed out on important information such as HIV/AIDS, Even though women are aware of where to get health information, they did not go to seek treatment due to ignorance and lack of information on what the health centres can do in educating, promoting, and disease prevention. This means rural women lack understanding of various diseases, symptoms, cure and medication.

There was limited use of libraries and rural informationcentres. This is in contrast with Dent (2006) who recommends the use of community health centres or libraries which have existed in Africa for more than 35 years. Rosenberg in her study of (1993) advocates for village reading rooms which can help in the dissemination ofhealth information to rural women. Thus, establishment of information centres or libraries in rural areas may help to overcome issues of illiteracy and ignorance which are some 


\section{International Journal of Science and Research (IJSR) \\ ISSN (Online): 2319-7064}

Index Copernicus Value (2013): 6.14 | Impact Factor (2015): 6.391

of the characteristics of rural dwellers. According to Momudu (2002) illiteracy in Africa is worsened by the fact that Africa does not have a reading culture, therefore reading health pamphlets and newspapers becomes a problem even to the educated women.

The study showed that health professionals disseminated somevarious information which included information on: HIV/AIDS, TB, Family planning, Immunization, Nutrition, Alcohol abuse, personal and environmental hygiene and so on. However, Kaane(1997) established that many such programmes in developing counties have lost focus and are curative. The results further revealed that majority women were not aware of the community information services and centres such as home based care initiative within the Public Health Care system which assists women on terminal diseases and community health workers which educates women on various diseases such as HIV/AIDS. In addition, most women were also not aware of voluntary testing and counselling centres, home visits, health talks, and family welfare educators, among others, and therefore did not get information on prevailing health problems and methods of preventing and controlling health problems confronting them.

Rural women experienced problems in accessing and using health information which included illiteracy, language barrier, lack of time, cost of travel, unreliable information sources, poor infrastructure, cultural practices, fear, andnegative attitude. Lack of access to health information curtailed rural women participation in socio economic development and rendered them ineffective in the fight against poverty and disease. They were not aware of adequate supply and proper nutrition, adequate supply of safe water and basic sanitation, maternal and child health, including family planning among others. Other problems cited by Odini (2009), in accessing and using information were high levels of poverty as women in rural areas would prefer to buy food than buy a newspaper, or purchase magazines to access health information.

Furthermore the utilization of electronic information resources (e - health) can only be realized when one has ICT knowledge and skills. The study findings sought to establish factors that hinder better utilization of ICT in accessing health information by rural women. The findings helped to confirm that if factors that contribute to poor utilization of ICTs in accessing and using health information are identified and well understood realistic alternatives and possible measures could be recommended to improve the situation. The findings established that rural women face technological and infrastructural barriers when accessing health information such as limited ICT facilities, insufficient skills, and lack of awareness, among others. Majority of respondents talked about lack of awareness about availability of ICT resources. This study supports a study by Sharma (2003) that rural women face problems in the use of ICTs in accessing health information.

\section{Conclusion}

The study findings established that age, level of education, marital status, occupation, and household income of women collectively affected the rural women's access to and use of healthinformation. These had significant impact on rural women's knowledge about their health problems. Women in Vihiga County expressed the need for various healthinformation which included: information on immunization, diarrhoea, STDs, common colds, pregnancy, skin problems, nutrition, personal and environmental hygiene, HIV/AIDs, among others. The study showed that women's information needs were not being met by the existing information sources, services and systems due to poverty, poor infrastructure, ignorance, distance to health facilities, beliefs and customs, cultural barriers, church beliefs, traditional medicine preferences, among others. Poor infrastructure in terms of roads, uneven distribution of electricity and telephone facilities accelerates the problems of accessibility and utilization of health information by the women. Therefore it can be concluded that these women are less informed on health matters and require health information to improve their healthstatus.

The study found out that women's health information needs were not adequately satisfied by the existing information sources such as friends, relatives, health centres, and neighbours. Women therefore tend to miss some information coming from external and conventional sources and get health information which may not be suitable for their daily access and use in healthcare. Similarly, women were not aware of the health information programmes that regulate access to and use of health informationin Vihiga County, rural Kenya. Hence, the need to disseminate personal health information in areas of family planning methods and gynaecological problems. However, there is ample opportunity for improvement if a number of issues related to access and use of health information are addressed. The improvement of electronicinformation coupled with training in ICT is crucial in order to enhance usage of ICTs by rural women. Concerning the use of e - health, study results showed that there was under - utilization of e - resources. It is concluded that rural women should be encouragedto exploit the benefits of $\mathrm{e}$ - health resources

\section{Recommendations}

Based upon the factors that hinder accessibility and utilization of health information by rural women which included poverty, illiteracy, ignorance coupled with limited awareness of availability of electronic resources, there is need to educate women on the value of health information so that they can make informed decisions regarding their health. Rural women should be sensitized about the importance of health information through putting more emphasis on the structures which are already put up by the government such as: health centres, home based care, health talks, home visits, and so on. Thus, rural women should be encouraged to go to the clinics where they can ask health related queries to ensure that they get access and use good and relevant health information. Ensure that messages meant to be received by women are relevant to their health priorities and are suitably presented. Information providers should repackage information in appropriate forms suitable for rural communities. In addition, radio and television stations should have sufficient rural related programming, and it should be broadcast at appropriate times. This will 


\section{International Journal of Science and Research (IJSR) \\ ISSN (Online): 2319-7064}

Index Copernicus Value (2013): 6.14 | Impact Factor (2015): 6.391

ensure that women have access to appropriate health education concerning prevailing health problems and methods of preventing and controlling them. This will enable them to better play their role as health providers, particularly at the family level.

The results of this study showed that rural women do not satisfy their health information needs in their bid to prevent or treat identifieddiseases because of their inability to use and access adequate health information. It is recommended that women's health information needs should be identified regularlyand understood in order to provide rural women with the right, current, and adequate information through various media. Examples of publicity may include: posters, women's groups, rural radio and television to create awareness. This will provide women with appropriate information and services for family planning, including infertility. Relevant information can enable women to access adequate food supply and proper nutrition, facilitate, and increase awareness of special nutritional information needs of women, especially during pregnancy and while breast - feeding. It could also enable women to access adequate informationon supply of safe water and basic sanitation,

It is recommended that the government should come upwith programs that disseminate and promote information on health education, concerning maternal health, child health, nutrition, communicable diseases, prevention and control of occupational health hazards environmental sanitation, and mental health. Provide education to women about safe motherhood and empower themto leadgood healthand alsoaccess health services. This can be done through workshops, demonstrations, the preferred format of sensitization, organize workshops and seminars to promote awareness, among planners and administrators dealing with data, of the importance of women's health and role in national and community development.An alternative policy option would be to set up information centres so as to enhance access and use of information. In that case, Government planners and decision makers, and international development partners should collect and disseminate information on current and relevant programmes and activities as a basis for effective planning and proper decision making in healthcare issues regarding women. Also collect basic information regarding national plans and programmes related to women's issues, including the mechanisms and structures that serve the women. This will improve data base on women issues such as health and development. They should also do research to identify specific factors indicating the relationship between women's health status and their role in healthcare of their families, the promotion of women's participation and overall national development, particularly in primary health care.

Since majority women were ignorant of their health issues, it is imperative for health information to be repackaged as a way of making the transmission and use easy. It should be repackaged in the form of music, drama, drawings, and pictures to help the illiterate to get the message. This may help the illiterate to be involved in their own health and therefore prevent some of the diseases and improve public health. It is observed that rural women lack current health information from health workers. It is recommended that increased number of skilled personnel in rural areas should provide relevant information toreduce health problems such as maternal and child mortality, including family planning, combat HIV/AIDS, and malaria, among other diseases. This would fill in for shortcomings of health talks, home visits, "barazas", which have not borne much fruit in the past.

The picture that emerged was that rural women use oral channels of communication. The use of information services such as telecentres and community libraries was limited.It is thus recommended that information centres be established in rural areas where rural women gather to listen to stories, watch films or read information materials collected from different sources in a simplified manner. This may be a single office within the village where there are qualified people present during the afternoons to impart knowledge in a friendly environment. This will not only get rural women to get used to reading, but also to get them to be open and talk about their health life experiences and getvaluable healthinformation in the process.

The information centres should be stocked with posters, pamphlets brochures books, films, newspapers, and any other information sources which can help supplement the knowledge women earn at the health centre or at home. This could support the fight against HIV/AIDs, among other health problems rural women face. These information centres should also be equipped with various information resources such as books, journals, radio. TV, internet, computers, e- mail, fax, and so on. Information during counselling should include information on breastfeeding, immunization, and family planning, treatment and prevention of malaria, among others. When rural women meet during group meetings, folk media such as dances, songs, storytelling, drama and poems, can be used to communicate certain themes on health. This kind of media enables women to participate actively in the communication of issues affecting them as a community. This can facilitate the collection and analysis of information on issues such as immunization and consequently, promote health education, prevent and control locally endemic diseases, seek appropriate treatment of women diseases and injuries.

Information providers should organize seminars and workshops to inform women about changes taking place within the health sector in the county, environment, and alert them on various issues pertaining to maternal health, HIV/AIDs, among other health related problems. To be more effective, these seminars should be organized near rural women's homes in a language they understand better for them to understand prevailing health problems and disasters among them and how to handle and manage them including the fight againstvarious diseases. Frequent exhibitions and demonstrations especially in the area of health should be used as a means of communicating to the rural women on health matters.

The study revealed that rural areas of Kenya lack the infrastructure to access current, timelyhealth information, it is recommended that the government should provide and improve rural communication infrastructure such as roads, rural electrification. This will strengthen health promotion 


\section{International Journal of Science and Research (IJSR) \\ ISSN (Online): 2319-7064 \\ Index Copernicus Value (2013): 6.14 | Impact Factor (2015): 6.391}

activities through mass media activities towards reducing and control of various diseases such as HIV/AIDS, TB, cancer, among other emerging diseases. At the same time put in place effective women's rural based information system programs whichcould enable women access and utilize health information to control the spread of various diseases in rural areas.At the same time ensure that health system infrastructure is in place to ensure that information gathered for evaluating health situations and trends and health systems should be suitable for assessing women's health needs. Health system research should be integrated within managerial process, to generate appropriate information to improve the planning of health systems in the county.

It was observed that rural women are not aware of strategies put in place to access and use information. It is recommended that proper structures, policies, and programs be put in place so as to provide rural women with health information. That is design strategies for the more active involvement of women organizations in health development. At the same time, visit women in their villages at individual levels in order to discuss any health information needs with them and problems that require higher level, and to promote research and dissemination of information on women's health. This can ensure that women are provided with appropriate information on drugs, appropriate health care facilities, and health legislation to facilitate the attainment of health objectives specific to women and Vision 2030. Information should be provided to women and women's organizations to make them aware of their rights and responsibilities for their own personal healthcare and that of their children. Promote awareness of the impact of working conditions upon health and the need for preventive measures against health hazards at work and encourage teaching institutes to include information about women's health roles in their curricula.

Findings showed that rural women did not use ICTs in accessing health information, there is need to improve ICT infrastructure and empower women through ICTs such as mobile phone to access quality and timely information which could enable them to make proper decisions about their health. This can be done through the government providing ICT infrastructure, improve internet connectivity/ bandwidth, provide ICT training to rural women, and ensure technical assistance and support, promote research on women, and involve women in health promotion on disease prevention. Formulate a monitoring system on the health status of women by undertaking research to help identify problems and needs specific to women of various groups, with particular referenceto improving women's health.

\section{References}

[1] Amoth, D.A. (2000). The use of information workers in Primary Health Care programmes in Siaya District. Unpublished. M.Phil. Thesis Moi University, Kenya.

[2] Bii, Harrison J. and Otike, J. (2003). Provision and accessibility of Health Information to the rural Communities in Kenya: A case study of Bomet District, Africa. Journal of Library and Archives \&Information Sciences. Vol. 13, No. 2, pp. $155-174$
[3] Crosby, A. (2006). Research Methods in health promotion; San Francisco: Jon Wiley.

[4] Kaane, S, I. (1997). A study of the effectiveness of visual media in the promotion of child immunization in Kakamega District, Kenya. A Doctoral Thesis. Loughborough University of Technology, U.K.

[5] Mchombu K. J. (1993) Information Needs and Seeking Patterns of Rural People's development in Africa. Gaborone, Botswana: Print and Pub. Co.

[6] Ngimwa, P et al., (1997). Media accessibility and utilization by Kenyan rural women. International Information and Library Review.Vol. 29, pp. 45 -66.

[7] Odame, H. H. (2002). Men in women's groups; evidence from Western Kenya, In: F. Cleaver (ed.) Men and women in Development. London: Zed Press.

[8] Ojiambo, J. B. (1993). Information User Studies. In: D. N. Ocholla, and J. B. Ojiambo (Eds.), Issues in Library and Information Studies. Nairobi: Jomo Kenyatta Foundation

[9] Raseroka, Kay H. (1990). Constrains in the provision of information services to women in the region; a social cultural analysis. Information for Women in Development. SCESCAL X1 Proceedings Kampala, Uganda. Pp.158-166.

[10]UNESCO (2005). Taking stock: Women's Empowerment Ten Years after Beijing. Paris: UNESCO

[11] United Nations Commission on the Status of Women (2003). African women and information communication technologies. New York: United Nations.

[12] Waswa, Julliex M. (2004). Information for rural women in small- scale enterprises; the role of public library service in Kenya. Paper presented at SCECSAL XV1 